\title{
COBRANCAS, ESTRATÉGIAS E "JEITINHOS": AVALIAÇÕES EM LARGA ESCALA NO RIO DE JANEIRO
}

RODRIGO ROSISTOLATO

ANA PIRES DO PRADO

SILVINA JULIA FERNÁNDEZ

\section{RESUMO}

O objetivo deste artigo é descrever e analisar visões de gestores da rede municipal do Rio de Janeiro sobre as avaliações em larga escala e seus reflexos no cotidiano escolar. Os dados foram mapeados em quatro grupos focais, dois com diretores e dois com profissionais da gestão central e intermediária da Secretaria Municipal de Educação. Demonstraremos que, apesar de as avaliações externas ainda se apresentarem como eventos extraordinários ao cotidiano escolar, há uma tendência à utilização dos dados delas resultantes como norteadores das práticas de gestão, mesmo com o desconhecimento técnico das avaliações. Foi possível perceber um "efeito dominó". Trata-se de um conjunto de cobranças sucessivas aos agentes de acordo com sua posição na hierarquia da gestão, que induz estratégias para methorar o desempenho institucional, assim como "jeitinhos" e estratagemas orientados pela expectativa de aumentar os índices das escolas.

PALAVRAS-CHAVE AVALIAÇÃO dOS SISTEMAS DE ENSINO • COTIDIANO ESCOLAR • PRÁtICAS DE GESTÃO • RIO DE JANEIRO. 


\section{RESUMEN}

El objetivo de este artículo es describir y analizar visiones de gestores de la red municipal de Rio de Janeiro sobre las evaluaciones en larga escala y sus reflejos en el cotidiano escolar. Los datos fueron mapeados en cuatro grupos focales, dos con directores y dos con profesionales de la gestión central e intermedia de la Secretaría Municipal de Educación. Demostraremos que, a pesar de que las evaluaciones externas todavía se presentan como eventos extraordinarios al cotidiano escolar, hay una tendencia a la utilización de los datos resultantes como ejes de las prácticas de gestión, incluso con el desconocimiento técnico de las evaluaciones. Fue posible percibir un "efecto dominó". Se trata de un conjunto de exigencias sucesivas a los agentes de acuerdo a su posición en la jerarquía de la gestión, que induce estrategias para mejorar el desempeño institucional, así como "jeitinhos" y estratagemas orientados por la expectativa de aumentar los índices de las escuelas.

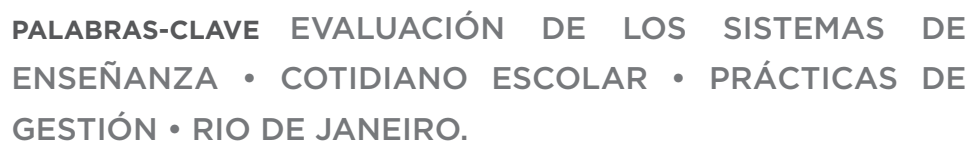

\section{ABSTRACT}

The objective of this article is to describe and analyze views of managers of the municipal network of Rio de Janeiro regarding the large-scale evaluations and their consequences in school daily life. The data were divided into four groups, two with directors and two with central and mid-level management professionals in the Municipal Department of Education. We will demonstrate that, despite external evaluations still being extraordinary events in school daily life, there is a tendency to use their resulting data as guidelines for management practices, even with technical lack of knowledge about the evaluations. It was possible to notice a "domino effect". This involves a set of successive demands on agents, according to their position in the management hierarchy, which induces strategies to improve institutional performance, as well as "jeitinhos" and stratagems guided by the expectation of increasing the indices of the schools.

KEYWORDS EVALUATION OF INSTRUCTIONAL SYSTEMS • SCHOOL DAILY LIFE - MANAGEMENT PRACTICES • RIO DE JANEIRO. 


\section{INTRODUÇÃO}

A proposta deste texto é descrever e analisar visões de gestores da rede municipal do Rio de Janeiro sobre as avaliações em larga escala e seus reflexos no cotidiano escolar. Trabalharemos, especificamente, com três questões. Indicaremos as opiniões dos profissionais sobre as avaliações em larga escala, suas visões sobre as demandas presentes no cotidiano escolar após a consolidação das avaliações e as estratégias e as resistências relacionadas ao desempenho das escolas. Analisaremos as dissonâncias existentes entre as perspectivas apontadas pelos diferentes níveis de gestão.

A investigação faz parte das problemáticas desenvolvidas no Laboratório de Pesquisa em Oportunidades Educacionais (LaPOpE) e está diretamente relacionada ao debate nacional sobre avaliação de sistemas educacionais. Demonstraremos que, embora as avaliações em larga escala ainda sejam eventos extraordinários ${ }^{1}$ ao cotidiano escolar, tendem a se consolidar como um dos elementos norteadores das práticas de gestão e docência. Há, no entanto, diferentes níveis de entendimento e ação. Ao mesmo tempo em que 
mapeamos estratégias com vistas a ampliar o desempenho das escolas, percebemos "jeitinhos" 2 e estratagemas orientados pela expectativa exclusiva de aumentar os índices das escolas.

É possível dizer que o cenário plural que será descrito está associado, entre outros fatores, às dificuldades enfrentadas por gestores para entender os aspectos técnicos relacionados às avaliações externas e seus índices. Nesse sentido, podemos indicar que a demanda por utilização de dados para organização de processos de ensino e planejamento escolar cresceu. Por outro lado, a oferta de formação especializada manteve-se limitada ou quase inexistente. Talvez esse seja um dos principais dilemas relacionados às políticas de avaliação de sistemas educacionais no Brasil.

Em outros contextos, a percepção de que educadores devem entender dados educacionais produzidos em larga escala cresceu em concomitância com a ampliação dos dados disponíveis (MARSH; PANE; HAMILTON, 2006; MANDINACH; GUMMER, 2013). Nesses contextos, a discussão gira em torno da necessidade de ampliação da formação para uso de dados, inclusive na formação de educadores. No caso brasileiro, especificamente no Rio de Janeiro, demonstraremos que há desconhecimento, dúvidas e ausência de preocupações relacionadas à formação para uso dos dados, o que, de certa forma, pode estimular estratégias antirrepublicanas ${ }^{3} \mathrm{e}$ "jeitinhos" diversos para produzir índices artificiais de sucesso, sem efeito para uma abordagem fidedigna da situação dos sistemas educacionais no Brasil.

\section{METODOLOGIA}

Durante o ano de 2012, realizamos dois grupos focais com gestores da rede municipal de educação da cidade do Rio de Janeiro. Os grupos foram compostos por profissionais de escolas de alto desempenho e de baixo desempenho separadamente. A definição de alto e baixo desempenho levou em consideração as notas obtidas pelas escolas na Prova Brasil de 2009. ${ }^{4}$ Como as notas vão de 0 a 10 em Língua Portuguesa e Matemática, dividimos as escolas em tercis. ${ }^{5}$ Classificamos
2 Para um debate sobre a "cultura do jeitinho" nas relações dos agentes sociais com o Estado republicano no Brasil, ver Da Matta (1983). Ver também Barbosa (1982). 3 Consideramos estratégias
antirrepublicanas quaisquer práticas
sociais que visem burlar as regras
universais formalmente estabelecidas
pelo Estado Democrático de Direito.
4 Utilizamos a nota padronizada da Prova Brasil.

5 Todos os cálculos relacionados à amostra foram realizados pela socióloga Mariane Campelo Koslinski. 
6 Seguindo os critérios mencionados, foram selecionados para o grupo focal de alto desempenho 11 gestores e para o grupo de baixo desempenho, 16 gestores.

7 A rede municipal do Rio de Janeiro é dividida em coordenadorias regionais de educação (CREs) Priorizamos a quarta CRE em virtude

da diversidade socioeconômica presente na região e da pluralidade de escolas com alto e baixo desempenho.

8 As justificativas para não participar das atividades da pesquisa foram em geral, relacionadas a outro compromisso já agendado na escola ou à falta de pessoal que possibilitasse a ausência do gestor na unidade escolar.

9 Não podemos descrever cargos e funções porque colocaríamos anonimato dos participantes em risco. as escolas do primeiro tercil como de alto desempenho e as do terceiro tercil como de baixo desempenho. Na sequência, selecionamos as escolas e convidamos os gestores. ${ }^{6} \mathrm{~A}$ escolha não foi totalmente aleatória porque priorizamos as escolas localizadas na região da quarta Coordenadoria Regional de Educação (CRE). ${ }^{7}$ Dentre os convidados das escolas de alto desempenho, apenas três compareceram. Tivemos a participação de nove gestores no grupo focal das escolas de baixo desempenho. ${ }^{8}$

Após a realização dos grupos focais, iniciamos um curso de formação para gestores da rede municipal de ensino do Rio de Janeiro dedicado às avaliações em larga escala. Para a primeira turma do curso, selecionamos profissionais alocados na gestão central e na gestão intermediária da Secretaria Municipal de Educação (SME). Decidimos realizar, antes do início dos encontros, um grupo focal com a equipe central e outro com integrantes da gestão intermediária. A proposta era mapear suas percepções sobre as avaliações em larga escala antes do início das aulas e seguindo o mesmo roteiro do grupo focal realizado com gestores. Todos optaram por participar da seleção para o curso e foram voluntários para a realização do grupo focal. O critério de seleção dos profissionais foi sua presença em cargos da gestão central e/ou intermediária da SME. Selecionamos um profissional de cada CRE - são 11 ao todo - e quatro profissionais da gestão central. ${ }^{9}$

$\mathrm{O}$ roteiro dos grupos focais foi o mesmo utilizado com os gestores de escolas de alto e baixo desempenho. Ele foi construído com o objetivo de mapear as percepções, o conhecimento técnico, a experiência, a relação entre avaliação e funcionamento da escola, as consequências/mudanças no cotidiano das escolas e as opiniões sobre a divulgação pública dos resultados. Neste artigo, analisaremos os dados produzidos nos quatro grupos focais, considerando as convergências e as divergências presentes nas falas de gestores que trabalham em escolas, na gestão central e/ou intermediária. 


\section{O DEBATE ACADÊMICO SOBRE AVALIAÇÃO EDUCACIONAL NO BRASIL}

As avaliações em larga escala surgem, nos anos 1990, como uma das principais novidades no campo educacional brasileiro. Naquele momento, os debates sobre a universalização do acesso à educação básica estavam perdendo força em virtude da própria universalização, e as discussões sobre a equalização da distribuição de conhecimento escolar ganhavam território. Havia clareza sobre a necessidade de avaliar os sistemas educacionais, o que motivou as decisões técnicas e políticas que deram origem ao Sistema de Avaliação da Educação Básica (Saeb).

O Saeb oferecia uma visão panorâmica do desempenho dos sistemas educacionais. Tratava-se do primeiro passo da construção de bases de dados que permitissem a formulação de políticas educacionais e, simultaneamente, fomentassem o debate acadêmico sobre educação no Brasil. O sistema foi modificado com a criação da Prova Brasil, que ampliou o escopo da avaliação e, consequentemente, o volume de dados disponíveis. Essa mudança expandiu as possibilidades analíticas, além de exacerbar os debates públicos sobre as avaliações em larga escala no Brasil.

É possível afirmar que as avaliações transitaram, em um período curto de tempo, do total desconhecimento para o centro da arena pública de debates sobre a educação no Brasil (ROSISTOLATO; PRADO, 2014; BONAMINO, 2002, BONAMINO; SOUSA, 2012). Essa transição ocorreu em duas vias paralelas. Por um lado, há intenso debate sobre os possíveis impactos das avaliações no cotidiano das escolas, incluindo gestão e trabalho docente (BONAMINO; COSCARELLI; FRANCO, 2002; SOUSA, 2003; CARVALHO; MACEDO, 2011; BONAMINO; SOUSA, 2012). Na outra via, seguem as pesquisas que discutem os desenhos técnicos dos sistemas de avaliação e os dados que eles podem produzir (ALVES, 2007; SOARES, 2009).

Esses dois conjuntos de pesquisas agregam ramificações que envolvem estudos sobre efeito escola, perfis de gestores e modelos de gestão, avaliação institucional e implementação de políticas educacionais (MARTINS; SOUSA, 2012). Trata-se de um campo dinâmico em que investigações 
10 Para a produção nessa temática ver Silva et al. (2013), Mesquita (2012) Pimenta (2011) e Fernandes (2010)

11 Esse debate pode ser visto em Mandinach, Honey e Light (2006). sobre a concepção e a estrutura dos sistemas de avaliação (BONAMINO; SOUSA, 2012; FRANCO; BONAMINO, 2001) convivem com pesquisas claramente orientadas pela negação das avaliações externas como caminho para a equalização da distribuição de conhecimento escolar no Brasil (FREITAS, 2012). Essa pluralidade de interpretações revela o dissenso ainda presente nas reflexões sobre sistemas de avaliação em larga escala no Brasil.

Nesse conjunto de pesquisas, há duas temáticas convergentes. Trata-se do debate sobre o uso de indicadores educacionais no cotidiano escolar - e nas instâncias intermediárias e centrais de gestão - e da formação para o uso. Sobre a primeira temática, desde 2009, observa-se na produção acadêmica brasileira uma reflexão sobre a compreensão e o uso dos indicadores educacionais nas escolas e/ou nas redes de ensino. Argumenta-se que há um aumento das avaliações em larga escala no país, mas ainda são reduzidas sua compreensão e utilização pelos agentes educacionais. ${ }^{10}$ Sobre a segunda temática, é possível afirmar que ainda é pouco explorada no Brasil, embora existam debates consolidados no cenário internacional. ${ }^{11}$ Em tese, as discussões sobre avaliação em larga escala deveriam incluir propostas claras para a divulgação dos resultados e incentivo ao uso, incluindo cursos de formação e incorporação desse debate na graduação de gestores e professores. No entanto, essas reflexões não estão, necessariamente, articuladas.

Brooke e Cunha (2011) apontam que na atualidade a maior dificuldade está no uso de indicadores para a orientação do trabalho de professores. No campo da gestão, porém, há ampliação de políticas de gestão orientadas e/ou fundamentadas por indicadores educacionais. O destaque dos autores é interessante porque permite perceber algum distanciamento entre professores e gestores quando o tema é a utilização dos indicadores produzidos pelos sistemas de avaliação educacional. Em princípio, gestores e professores seriam mutuamente dependentes, mas na prática essa interdependência pode não ocorrer.

Fontanive (2005) já indicava as possibilidades de uso pedagógico dos testes e alguns dilemas presentes na disseminação 
dos resultados produzidos por avaliações em larga escala. A autora defendia explicitamente a divulgação pública e a popularização do uso das avaliações em larga escala. Ela frisava a possibilidade de ampliação de relações democráticas e equânimes na distribuição de conhecimento escolar com a divulgação e o consequente entendimento dos dados. Também apontava alguns problemas que poderiam ser causados pela ausência de conhecimento técnico, como a ênfase no treinamento de estudantes e a ampliação da competitividade negativa entre as escolas na mesma rede de ensino.

Em 2013, a Fundação Carlos Chagas publicou os resultados de uma pesquisa sobre os usos da avaliação externa por equipes gestoras e profissionais docentes (SILVA et al., 2013). Os dados indicam uma série de usos e também "abusos" relacionados à ênfase em simulados e preparação para provas, além de preocupações referentes à possibilidade de as avaliações ampliarem a ênfase em classificações hierarquizadas de escolas e alunos. O relatório também aponta a pluralidade de interpretações relacionadas aos índices educacionais e, principalmente, ao tipo de resposta que as escolas deveriam oferecer à política educacional.

Essa pluralidade é significativa porque permite perceber um tipo específico de desconhecimento com relação às políticas de avaliação educacional. Os gestores entendem que precisam responder à avaliação melhorando o fluxo e as notas das escolas - em alguns casos a qualquer custo. Essa interpretação diverge da proposta original. Se observarmos o desenho das políticas de avaliação, a expectativa é diferente. Espera-se que os dados permitam que gestores e professores tenham um panorama do desempenho de suas escolas em mãos para que possam produzir diagnósticos relacionados às causas do desempenho e, se for o caso, trabalhar para a ampliação de práticas pedagógicas e de gestão que possam melhorar a escola, o que, consequentemente, melhorará os índices.

Neste artigo, trabalhamos com a hipótese de que esse desconhecimento está relacionado à ausência de processos de formação articulados à implementação de políticas de avaliação em larga escala e divulgação de dados educacionais. 
Não há, no Brasil, uma política de formação para o uso de dados, o que contribui para a pluralidade de interpretações. Tanto aquelas relacionadas ao que se deve fazer com eles, assim como aos tipos de respostas cabíveis quando é necessário explicar para as redes de ensino, ou para o público em geral, o desempenho de uma escola.

A utilização de dados para tomada de decisões relacionadas aos sistemas educacionais tem sido discutida - no contexto internacional - como um dos focos centrais da política e da prática educacional. A proposta é que os encaminhamentos referentes aos sistemas educacionais e às escolas sejam realizados com base em dados que permitam avaliações fidedignas sobre os problemas em foco (MARSH; PANE; HAMILTON, 2006). Por isso, há intensos debates sobre a necessidade de formação inicial e continuada para gestores e professores. A ideia é permitir que ambos conheçam os dados educacionais e consigam utilizá-los em suas tomadas de decisão (MANDINACH; GUMMER, 2013). A proposta é que essa formação seja sistemática e articulada à teoria e à prática dos novos educadores.

No Brasil, ao contrário, não há debates voltados especificamente para o treinamento de profissionais para o uso de indicadores educacionais. É importante considerar que nossos sistemas de avaliação e produção de dados são recentes, assim como o debate técnico e político sobre as possibilidades e os limites desse modelo de política educacional. Talvez por isso ainda não tenhamos avançado no planejamento para o uso.

A ausência de formação, no entanto, convive com as exigências relacionadas ao uso de dados para planejamento. Por mais que pareça incongruente, é possível dizer que se espera que gestores, mesmo sem conhecimento, usem os dados para o diagnóstico e a organização de atividades escolares. Cabe, portanto, analisar os reflexos desse modelo de política educacional no cotidiano dos gestores e pensar suas respostas às novas dinâmicas trazidas pelas avaliações em larga escala e pelos dados por elas produzidos.

Nosso contexto de análise é o Rio de Janeiro. Trata-se de um município que participa da Prova Brasil e possui um 
sistema próprio de avaliação das escolas, também utilizado para bonificação de professores: a Prova Rio. É possível dizer que ambas - Prova Brasil e Prova Rio - causam efeitos específicos nas gestões central e intermediária, além de atingirem diretamente as escolas e os professores. Por isso, nossas questões de pesquisa estavam relacionadas às percepções sobre as avaliações e as possibilidades de usos efetivos dos indicadores para o planejamento educacional.

\section{PERCEPÇÕES E EXPECTATIVAS \\ COMO GESTORES ANALISAM E COMPREENDEM OS DADOS}

As avaliações em larga escala colocam o universo da escola e dos profissionais diretamente envolvidos com elas em xeque. São eventos extraordinários ao cotidiano escolar, ${ }^{12}$ mas, paradoxalmente, têm influenciado as interações entre os agentes presentes na escola e as relações entre as escolas e os diferentes níveis de gestão.

A progressiva acomodação dessa novidade extraordinária no cotidiano ordinário da escola e das atividades dos gestores do nível central não se reflete, necessariamente, no conhecimento das avaliações externas, de suas propostas e de seus resultados. No nível central, o conhecimento sobre as avaliações externas é restrito a um grupo que trabalha no setor responsável pelos dados e análises das avaliações. Esse grupo também é responsável pela posterior transmissão dos resultados a outros setores da SME,,$^{13}$ que geralmente têm dúvidas sobre os indicadores e os resultados. Os membros da gestão central reconhecem a dificuldade para compreender e explicar as análises das avaliações externas, principalmente pelo fato de envolverem uma lógica distinta da usual, como afirma a Entrevistada 1, do grupo focal de gestores da SME: "Esse negócio que o professor fala, uma acertou vinte e a outra acertou vinte e não ficaram com a mesma nota. Aí, explicar isso para o professor é difícil, que a lógica é outra, que não são as mesmas questões, enfim. Difícil explicar."

Na gestão intermediária, nas CREs, há uma dificuldade de compreender como se obtém determinado resultado e
12 A oposição entre os universos ordinário e extraordinário é um recurso analítico utilizado para destacar as diferenças entre as atividades mais cotidianas - da ordem e previsiveis - e as atividades que problematizam o cotidiano extraordinárias e nada previsiveis (ROSISTOLATO; PRADO, 2014).

13 Neste artigo, optamos por não descrever detalhadamente o organograma de gestão da SME. O objetivo é preservar a identidade dos gestores que participaram dos grupos focais. 
quais elementos entram no cálculo dos indicadores educacionais, conforme indicam as falas do grupo focal:

Entrevistada 2: Essa fórmula ai é complicado. A gente tenta decifrar.

Entrevistada 3: Eu já tentei decifrar, mas é complicado. A gente sabe alguns elementos que compõem.

Mediadora: Quais são esses elementos?

[Muitas vozes ao mesmo tempo falando em "desempenho" $e$ "reprovação", "retenção", "evasão".]

Entrevistada 3: Entra o IDH também! A evasão, retenção, desempenho. (Grupo focal, gestores CRE)

Como alguns gestores do nível central e intermediário relataram, eles têm como atividade dialogar com as escolas sobre os resultados das avaliações. No entanto, o desconhecimento fez com que estudassem individualmente os indicadores para cumprir sua tarefa, algo que não era efetuado anteriormente. Os gestores justificam suas dificuldades de compreensão em virtude do desconhecimento de estatística.

Entrevistada 1: A gente vai analisar os números, cresceu onde?

Cresceu como? Ou diminuiu? Onde e como?... Como que esse resultado caiu? Onde que você tem que investir e que tipo de retorno você pode querer? Então você se debruça sobre esse resultado. Agora, por exemplo, recebemos o resultado da Prova Rio, então eu paro para tentar entender isso. Então, por exemplo, eu fiz Pedagogia e a estatística para mim é muito complicada, então para a escola também. Então eu me forço a estudar aqueles dados para isso. Eu não tinha esse hábito. Mas eu quero entender e esmiuçar isso para poder conversar com o coordenador pedagógico. (Grupo focal, gestores CRE)

O desconhecimento das avaliações externas nos níveis central e intermediário tem reflexo direto nas escolas. Os diretores questionavam as avaliações externas, não por seus cálculos, mas por não saberem o que estava sendo avaliado e seus objetivos. Nos dois grupos focais com diretores, observamos silêncio e desconforto quando perguntávamos sobre o cálculo dos indicadores e seus significados.

Mediadora: Vocês sabem como se chega a esse índice?

Entrevistada 4: 0 cálculo? 
Mediadora: É, o cálculo...

Entrevistada 4: É, eu já tive essa curiosidade... Até já estudei isso, não profundamente, mas para ter uma noção... Não é assim uma coisa que eu domino... Mas uma noção eu tenho... [...]. Não é só a avaliação não, envolve...

Entrevistada 5: É evasão e o desempenho da escola como um todo. (Grupo focal, gestores alto desempenho, Rio de Janeiro)

Mesmo com o desconhecimento, há uma visão compartilhada entre os gestores dos diferentes níveis de que as avaliações externas estão criando novas demandas no cotidiano escolar e na própria gestão da rede. Para membros da secretaria, as avaliações externas centralizaram as ações da gestão, pois todas as atividades estão relacionadas a elas.

Entrevistada 6: Quem utiliza os resultados é quem está ligado ao processo de ensino-aprendizagem [...]. Mas, por exemplo, temos a coordenadoria de RH. Ela provavelmente não mexe diretamente com esses dados, mas talvez indiretamente [...].

Entrevistada 7: Eu acho que hoje se trabalha muito em função dos resultados das avaliações. (Grupo focal, gestores SME)

Uma gestora da SME exemplifica a nova situação como um "efeito dominó": a secretaria exige da CRE, que exige da escola. A escola, por sua vez, demanda à CRE algumas ações e procura a secretaria para ajudá-la nessa função.

Entrevistada 7: Vira um efeito dominó porque as CREs estão mais interessadas e cobrando das escolas porque as escolas também estão cobrando delas coisas bacanas para melhorar as suas escolas. As diretoras estão em cima da CRE para melhorar a sua escola, a CRE em cima da gente, vira um efeito dominó. (Grupo focal, gestores SME)

Seguindo essa lógica do "efeito dominó", as gestoras das CREs indicaram que mudaram suas funções: se antes fiscalizavam, agora são "parceiras" das escolas, até porque também são cobradas pelos resultados das avaliações externas.

Entrevistada 3: A partir de 2009, mais em 2010, pelo menos na nossa CRE, esse othar fiscalizador, essas visitas fiscalizadoras, perderam lugar para esse olhar, para essa parceria. 
Entrevistada 8: Porque a cobrança é grande, né gente?

Entrevistada 3: Ou seja, não para acusar e sim para nortear algumas coisas que precisam ser mudadas. A postura da CRE mudou.

$[\ldots]$

Entrevistada 5: Quanto aos resultados, hoje a escola sente mais confiança na gente, nas parcerias, a gente senta com ela pra olhar esses indices. Porque eles estão ali, não tem como esconder. O rei está nu. Salvo uma ou outra, elas se sentem mais à vontade para conversar. (Grupo focal, gestores CRE)

Há uma dissonância entre o que pensam diretores e as CREs sobre a mudança nas atividades e o cotidiano escolar com a introdução das avaliações externas. Por um lado, os diretores indicam que a gestão escolar e o trabalho de sala de aula estão direcionados para as avaliações em larga escala. Para eles, a Prova Rio e a Prova Brasil ainda são eventos extraordinários. No entanto, todo seu trabalho está relacionado às demandas das avaliações, seu treinamento, aplicação e resultado.

Por outro lado, para os gestores das CREs as avaliações externas têm produzido um fenômeno novo nas escolas: os professores e diretores têm se conscientizado da necessidade de mudança em sua prática pedagógica. A partir dos resultados das avaliações externas, as escolas começam a pensar em sua forma de avaliar, em suas práticas e nas maneiras de modificá-las. As avaliações externas, portanto, trouxeram algo novo para a organização escolar porque passaram a englobar todos que nela trabalham.

Entrevistada 3: Tem uma questão, do tempo que a escola ficou no seu mundo, uma colega usava uma expressão, era o "jeito doméstico de ser". Então, quando vem uma avaliação externa, [...] uma necessidade de universalizar ou de homogeneizar o ensino do país, [...] mas trouxe, eu acho, essa mexida, na escola, fabulosa. Quer dizer, eu não faço o que eu quero.

[...]

Entrevistada 8: É muito legal a gente ouvir colegas dizendo "eu fiz isso na minha sala". E ele achava, algum tempo atrás, que aquele conteúdo não dava. Ele falava que meu aluno da escola 
pública não vai aprender isso, não. E ele viu que o aluno consegue aprender e que tem uma avaliação que cobra isso dele.

Entrevistada 3: Não é o jeito doméstico de ser.

[...]

Entrevistada 9: Muitas vezes a escola faz o seu planejamento, do que vai ser ensinado, do que vai ser cobrado, o que vai ser avaliado e, aí, passou pelas provas externas e tem consciência do que precisa ser trabalhado. Não importa se o aluno é da escola pública ou da escola privada, aquilo precisa ser trabalhado. Então, isso foi uma mudança para os alunos, para os professores e, a meu ver, foi uma mudança positiva.

Entrevistada 2: Hoje acabou aquela ideia de um cofre que fica dentro de outro cofre, que fica dentro de outro cofre. Porque a sala de aula tinha muito aquela coisa do professor de "fechei a porta, eu faço o que eu quero. Eu sou o dono do saber e esta é a minha sala". E a coisa ficava "tão minha", "tão minha", que não podia sair nem daquele espaço físico. E o gestor acaba fazendo a mesma coisa, "é a minha escola, dos meus alunos". Então, hoje essa visão tá um pouquinho diferente [...].

Entrevistada 3: Porque agora esse professor já não acha mais que ele é um ser unicelular, ele já começa a perceber que ele faz parte de um conjunto de células e a coisa tem que funcionar de outras formas. (Grupo focal, gestores CRE)

Os gestores indicam outra dissonância entre diretores e gestão intermediária, que diz respeito às diferenças entre as avaliações externas - Prova Brasil e Prova Rio - e internas, conhecida como Prova Bimestral. Para os diretores, as avaliações realizadas pela rede são mais fáceis porque englobam o que foi trabalhado nos cadernos pedagógicos. Ao passo que as avaliações externas são mais difíceis e exigem outros conteúdos. Segundo eles, essas diferenças criam um problema para o gestor porque este tem que pedir aos docentes que trabalhem com o material dos cadernos pedagógicos ou com o conteúdo das avaliações externas.

A gestão da CRE analisa positivamente esse movimento. As diferenças fazem com que o diretor e o professor comecem a refletir sobre seu trabalho e a propor mudanças em sua prática pedagógica. 
Entrevistada 8: Isso leva também a escola a pensar no que ela está fazendo, né? O cara viu que, quando pega uma prova que já passou, e ele viu que ele pode fazer aquilo. Porque a gente ficou muito tempo achando que tinha que ser aquele conteúdo, aquela atividade, só aquela, aquele formato, aquele formato para aluno da escola pública, que o aluno só podia aprender até ali, então, agora a gente vê que tem colegas que percebem que ele pode ir além, que ele tem condições [...]. E aquele cara que pega o resultado da avaliação externa, que se debruça em cima, ela também leva a refletir dessa forma. (Grupo focal, gestores CRE)

Outra mudança significativa relaciona-se à divulgação pública dos resultados. Segundo os gestores da secretaria, esse é um dos objetivos centrais da atual gestão: aproximar os pais da escola, utilizando como meio de mobilização a imprensa e a divulgação dos resultados educacionais para a sociedade.

Mediadora: E nessa mudança vocês perceberam algo nas atitudes de alunos, nas famílias dos responsáveis?

Entrevistada 7: Tem até preocupação de pais ligando para saber resultado de escola tal, para saber onde vai matricular o filho. Está tendo até uma procura dos pais pelas escolas para decidirem onde vão matricular os filhos [...].

Entrevistada 6: Mas isso é um resultado de uma estratégia dessa gestão, que é realmente aproximar os pais das escolas, justamente com isso da prova, que é uma coisa que está na mídia, indice de escola, bota na porta, não bota na porta [...]. Eu acho que, com isso, você chama atenção para que os pais discutam a educação também. Eu acho que a gente caminhou para essa discussão estar na mídia e os pais se apropriarem. (Grupo focal, gestores SME)

Os gestores das CREs valorizam a divulgação pública dos resultados e o trabalho mais próximo aos pais e às famílias dos alunos. No entanto, diferentemente dos gestores da SME, apontam alguns problemas dessa relação que possibilitaram a "faxina pedagógica" realizada em algumas escolas após o resultado positivo nas avaliações externas.

Entrevistada 10: Isso é uma coisa que eu sou preocupada, sim, dos pais chegarem na porta daquela escola e rejeitarem aquela 
escola, rejeitarem aquela comunidade, abaixa mais ainda a autoestima daquela escola que está numa posição desprivilegiada, vamos dizer assim, que a gente não sabe que motivos são esses, será que é só isso mesmo, se é só mesmo problema de gestão, ou se falta participação desses pais, o que já falou aqui. Então, preocupa você ter uma escola lotada e outra do outro lado vazia porque tem uma placa do Ideb ${ }^{14}$ na porta dizendo que é 3.2 .

Entrevistada 2: 0 que me incomoda muito não énem a vazia, mas é a de nota alta fazer uma faxina pedagógica, uma higienização pedagógica. Isso me incomoda muito. (Grupo focal, gestores CRE)

Para os gestores, a divulgação pública dos resultados faz com que eles se preocupem com as avaliações e seus indicadores, como informa o Entrevistado 11: "É. No dia a dia do gestor, por causa disso: essa preocupação que ele tem, de como vai ser a sua escola, como ela vai ficar... de como ela vai ser vista. O retrato para a sociedade." (Grupo focal, gestores baixo desempenho, Rio de Janeiro).

Quando questionamos sobre o resultado das avaliações e se os índices retratavam as escolas de maneira fidedigna, encontramos uma visão uníssona nas coordenadorias e na secretaria: as avaliações externas não refletem totalmente a "nossa realidade".

No caso dos gestores da SME, há um questionamento das avaliações feitas pelo Ministério da Educação (MEC). Consideram importantes sua existência e sua aplicação, mas creem que elas não refletem o trabalho feito pela rede municipal. Sustentam sua posição apontando a ausência do olhar pedagógico nas questões, as avaliações centradas na Língua Portuguesa e na Matemática e, principalmente, a impossibilidade de comparar a rede carioca, segundo eles a maior do país, com outras redes.

Entrevistada 7: A gente pensa que essa rede é a maior de todas, então, a comparação já fica diferente. A quantidade de nossos alunos que faz a prova é grande, é uma rede grande e a gente incentiva que eles façam a prova. Além disso, a gente tem dado um salto maior de 2009 para 2011, especialmente num segmento que a gente sempre ia mais atrás. Os alunos, principalmente em Matemática, sempre nos deixavam mais atrás. No Brasil todo,
14 Índice de Desenvolvimento da Educação Básica. 
15 Índice de Desenvolvimento da Educação do Município do Rio de Janeiro. comparados com as outras capitais, nós não estávamos mal, levando em consideração o tamanho da nossa rede. Agora fomos lá pra cima.

Entrevistada 6: Temos que pensar também que as outras capitais dividem com o estado o ensino fundamental. O Rio não divide, é só ele. Então a gente vai da creche até o nono ano. Isso também é uma coisa que dificulta.

Gestora 1: Não tem como comparar. (Grupo focal, gestores SME)

As gestoras das CREs consideram as avaliações da rede mais fidedignas do que as avaliações nacionais. Dizem que elas refletem o trabalho realizado nas escolas por darem subsídios para diagnósticos e intervenções mais rápidas.

Entrevistada 12: É essencial, e no caso do Rio, eu acho que a gente acaba subestimando a avaliação nacional, porque acaba favorecendo algumas questões e outras não. As regionais, eu gosto mais, eu acho mais fidedignas.

Entrevistada 9: É, quando se faz essa prova especificamente para o Rio, a gente consegue analisar o trabalho todo, ver o que está funcionando e intervir com mais rapidez.

Entrevistada 10: O interessante é que tudo é no caráter de comparação de resultados, então, por exemplo, ano passado tinham escolas que ou tiveram um desempenho muito baixo na avaliação nacional ou um IDE-Rio ${ }^{15}$ baixo, só que na Prova Rio era diferente, ou para mais ou para menos. Se a escola está ruim em uma avaliação que só tem prova de Língua Portuguesa e Matemática, como que você fala que o desempenho da escola é ruim? A Prova Brasil, então, só tem dois anos, então a gente fica muito restrita nessa avaliação... Não dá para ser pontual. Há uma série de questões dentro da escola que interferem muito e que falam da escola. É meio por aí. Pela própria elaboração da prova e aplicação. Como que a gente deve olhar para esses resultados? É interessante, é importante, mas ocorreu uma coisa, que foi uma avaliação externa, mas a avaliação diagnóstica mostra resultados não tão esperados e isso se torna muito mais produtivo, melhor desenvolvimento do que a avaliação externa. Eu estou certa disso. Quando a gente vai tabular os resultados, acaba tendo elementos muito mais interessantes do que a avaliação externa. (Grupo focal, gestores CRE) 
Ainda segundo os gestores das CREs, as avaliações nacionais, principalmente por terem aplicadores externos, possibilitam dribles de alguns diretores e produzem indicadores que não refletem o trabalho e a realidade da escola.

Mediadora: Vocês acham que esses resultados refletem a realidade das escolas das CREs?

Entrevistada 10: Em algumas escolas até sim, mas outras nem sempre... Até porque, volto a dizer, as avaliações externas são pontuais em duas disciplinas somente. E aí pode ser um trabaTho focado nessas áreas e no restante a coisa não aparece, não acontece, aí saímos do individual para o coletivo, a escola como um todo não é lá essas coisas. Nós sabemos que tem diretores que dispensam os alunos com conceitos baixos para não fazer as avaliações. Assim como os alunos incluídos das turmas são convidados a não comparecer nesse dia [muitas vozes ao mesmo tempo]. (Grupo focal, gestores CRE)

Os gestores partem da ideia de que os resultados das avaliações externas não refletem a realidade da escola. $\mathrm{Na}$ concepção deles, respondem por um espelho social e não somente pelo trabalho pedagógico.

Entrevistada 13: O aluno que é excluído por abandono conta ponto no Ideb. Mas o que ocorre? [...] O que vai aparecer ali é o espelho do pedagógico de sua escola; agora, o que aparece de repente no Ideb é um espelho, não só o pedagógico; porque o que se deve cobrar da escola é o espelho pedagógico, né? Agora a gente acaba respondendo por um espelho social. (Grupo focal, gestores baixo desempenho, Rio de Janeiro)

Percebemos que as avaliações em larga escala têm transitado progressivamente para o mundo ordinário da escola e dos órgãos de gestão da rede municipal. Não houve, em nenhum grupo, visões que negassem as avaliações por princípio, mas há críticas relacionadas a sua aplicação e principalmente a sua compreensão. Os grupos focais indicam que os profissionais da educação ainda enfrentam dificuldades técnicas para compreender as avaliações externas, até mesmo aqueles responsáveis por analisá-las. 
O QUE OS GESTORES ACREDITAM QUE DEVEM/PODEM FAZER?

As diversas visões a respeito das avaliações em larga escala no material trabalhado trazem também uma série de interpretações a respeito das finalidades às que essas avaliações estariam respondendo e, em consequência, provocam diversas expectativas, nos diferentes sujeitos escolares, sobre o que se espera que cada um deles faça com ou com base nelas em sua ação cotidiana em função dessas finalidades.

Nesse sentido, a implementação dessas avaliações é interpretada pelos sujeitos como uma demanda de ação, balizada por seus entendimentos sobre as formas, os conteúdos e as finalidades supostamente apresentados pelas avaliações no cotidiano escolar. Ou seja, os sujeitos buscam antecipar futuros possíveis não apenas por meio da extrapolação de dados do passado ou das condições de produção e ação atuais em cada realidade escolar, mas também considerando a suposta finalidade técnica e/ou política implícita nas avaliações e a também suposta atuação esperada para cada um deles, de acordo com seu lugar institucional, evidenciando diversos sentidos prospectivos mais ou menos estratégicos. Cabe perguntar, portanto, quais são as percepções de gestores e funcionários da SME a respeito dos desafios e das possibilidades de ação a partir da introdução das avaliações em larga escala no cotidiano escolar.

Participando de uma visão mais estratégica, a proposta de aproveitamento dos dados das avaliações externas para a realização de um diagnóstico escolar aparece claramente apenas na fala de Entrevistado 14, gestor de escola de alto desempenho: "Eu percebo que, mesmo tendo uma origem de prestação de contas [...], nós podemos, sim, aproveitá-las para diagnóstico dos defeitos ou das falhas e fazer correções futuras".

Essa visão é compartilhada pelos funcionários da SME, destacando-se a menção às CREs como instância dinâmica na utilização desses indicadores para melhorar a qualidade educacional:

Entrevistada 1: As CREs mexem diretamente. A CRE mexe um bocado. Eu acho que setores lá na secretaria, aquele pessoal do 
material, eles vão usar os dados, como? Vão comprar equipamento para $x$ escolas, isso pode ser influenciado pelos resultados? Talvez possa. Vou equipar methor, vou verificar. Acho que todos os setores podem usar os dados. A secretaria inteira tá voltada com esses dados. Lógico que quem está mais diretamente ligado ao ensino-aprendizagem vai estar mais junto desses dados. Se pensa muito nas escolas que precisam de maior apoio. (Grupo focal, gestores SME)

Por isso, o interesse em facilitar a apropriação desses dados, para que possam ser estrategicamente aproveitados, é destacado na fala da Entrevistada 7: "Agora vai ter o boletim escolar, com todos os dados da escola, com análise com comentários, para a escola ter acesso ao boletim dela, com os pontos, os dados mais mastigadinhos para aquela escola." (Grupo focal, gestores SME).

Divergindo dessa visão, duas gestoras de escolas com baixo desempenho dizem que é necessário amadurecer o que fazer com os dados. Esse é o caso da Entrevistada 15, gestora de uma escola de baixo desempenho: "Eu acho que tem um processo de amadurecimento que passa pela nossa formação de aprender a lidar com esses instrumentos sem se descaracterizar e de incorporá-los, mas não substituí-los".

Compartilhando as dificuldades para lidar com esses dados, o Entrevistado 11, de escola de baixo desempenho, entende que eles são importantes para refletir sobre e motivar a equipe, mas isso em função das metas e do $14^{\circ}$ salário, e atendendo aos fatores retenção e fluxo como variáveis para melhorar a nota da escola:

Entrevistado 11: Eu reuni o grupo e comentamos: "Olha, vamos nos esforçar para conseguir ou não?" Aí todo mundo concordou. Porque não passa só pela prova do Ideb só para o $9^{\circ}$ ano. Então também influencia na aprovação, também, da escola [...]. Eu acho que também posso estar errado, mas eu acho que provocou nos professores que abraçaram a causa, em tentar se esforçar um pouco mais para ver se o aluno tem condições ou não de passar, porque antes, até o mesmo professor já passou uma prova, um teste, alguma coisa e não conseguiu, então deixa para lá, vai ficar com aquela nota mesmo. Porque se a escola reprovas- 
se bastante, como reprovou em 2009 e 2010, a gente não iria conseguir, não iria ganhar. E como ganhamos o IDE-Rio, que é o $7^{\circ}$ ano que faz a prova e eles sentiram o gostinho, que foi de 2010 para 2011, aí, no ano passado, em 2011, eles queriam de novo. (Grupo focal, gestores baixo desempenho, Rio de Janeiro)

A motivação também aparece como uma alternativa de ação escolhida pelos funcionários das CREs, que afirmam ter que "esperar o tempo de o professor [diretor]" superar o choque de receber resultados muito baixos. No entanto, chama a atenção o fato de que eles tampouco saibam explicar como se calculam os indicadores e, portanto, uma análise mais técnica e detalhada dos números pode ficar comprometida, apesar de ser com base e em função desses indicadores que se espera que a escola realize seu planejamento.

Entrevistada 16: Quando eu vou para dentro das escolas, daquelas escolas que ficam lá embaixo no ranking, quando eu sento com elas, eu pergunto pelo plano de ação, o que está ocorrendo, aí a gente começa a entender algumas coisas e a fazer com que ele pense aquilo ali de outra forma. Houve uma escola que o diretor sentou na minha frente e não parava de chorar quando conversamos. Aí eu falei "a gente tem que agora largar o luto e ir à luta”. E o nosso momento já passou por essas duas etapas, agora estamos mudando. (Grupo focal, gestores CRE)

Contudo, o desconhecimento sobre as avaliações e seus resultados, assim como mobiliza em alguns a vontade de querer entender melhor ou mesmo de "dar um jeito" de melhorar os indicadores - por meio da motivação da equipe ou de outras variáveis de peso sobre as que se teria maior controle, como o fluxo escolar -, também gera movimentos de resistência ou até de certa denúncia. Dessa forma, a articulação da equipe escolar não se apresenta como tarefa fácil e, mesmo em escolas com alto desempenho, as resistências de alguns professores para trabalhar com os dados advindos das avaliações são destacadas pela gestão:

Entrevistada 4: Então, quando você organiza uma reunião da coordenação e tal, "gente, vamos pegar o retorno, vamos analisar"... É uma resistência que vocês não têm ideia, né, e assim, 
lá na escola, a gente não trabalha para prova, não se trabalha para prova, a gente trabalha para o aluno, é a questão mesmo da formação. Se ele vai fazer a prova A, B, C ou se tem prova externa, é uma consequência, então a gente trabalha assim. (Grupo focal, gestores alto desempenho, Rio de Janeiro)

A resistência de alguns professores se manifesta de diversas formas, chegando inclusive a ações que beiram a temeridade política (MATUS, 1996, p. 174), rejeitando a realização das provas na escola em que trabalham:

Entrevistada 9: Na CRE [citando uma das 11 CREs], acontece uma coisa, particularmente, que não foi citada até agora, que é a resistência dos professores da maneira "não vou colaborar com isso, não concordo com isso, os meus alunos não vão fazer essa avaliação". Aí, no dia da avaliação, não tem aluno, não tem turma, porque eles são contra e não participam. E quando alguns ganham $14^{\circ}$, eles batem no peito e falam "não ganho, não concordo com isso". Então é uma questão muitas vezes, simplesmente, que se leva pelo senso comum. Nós temos uma situação extrema de uma escola em que todos os professores se recusam a cumprir as provas bimestrais. (Grupo focal, gestores CRE)

No extremo oposto, alguns gestores ficam apreensivos com relação à ação inercial, como resposta passiva, que pode ser escolhida por alguns professores e que parece estar acontecendo em algumas escolas:

Entrevistado 17: A gente tem que dizer, na minha escola também acontece, para o professor que ele não pode dar uma avaliação, botar a nota final só com a avaliação externa. Então isso, a culpa não é da avaliação externa, é culpa do profissional que eu não sei que palavra vou ter. (Grupo focal, gestores baixo desempenho, Rio de Janeiro)

Assumir essa inércia a ponto de não realizar mais a própria prova, ação escolar com amplíssima trajetória e legitimidade dentro do sistema educacional brasileiro, e depender exclusivamente da avaliação de outra instância institucional, pode presumir tanto a delegação como a suposta expropriação do poder de avaliação, no entendimento de 
que há uma perda substantiva de autonomia escolar, a partir do momento em que se deve "dividir" essa função com outras instâncias do sistema.

Entrevistada 18: A gente deixou de ser diretor e passou a ser gestor de algo que não nasce dentro da escola. E isso é muito sério. Entrevistada 19: E isso que eu estou falando, está afetando o nosso PPP. ${ }^{16}$ Eu senti isso. Eu acho que está afetando o nosso dia a dia. Entrevistada 18: Por outro lado, também, tinha escola que nem tinha PPP.

Entrevistada 19: Mas, por exemplo, a gente tinha planejamento. Entrevistada 18: Quer ver uma coisa, quando a gente falava de avaliação, eu lembro que, quando surgiu, lá atrás, a resolução, a portaria que determinava como seria a avaliação, muitos professores quicaram: "Não! Está tirando da gente a autonomia, o direito de fazer a nossa prova”. (Grupo focal, gestores baixo desempenho, Rio de Janeiro)

A suposta autonomia absoluta anterior que, como fica evidente na fala da Entrevistada 18, possibilitava que algumas escolas não se preocupassem em realizar seu planejamento institucional, aparece novamente na fala da mesma gestora, preocupada com o fato de que o professor não abra mão do planejamento, o que implicaria também abrir mão da autonomia. Mas isso requer, ao mesmo tempo, competência profissional para poder assumir seu papel no sistema educacional.

Entrevistada 15: Outro dia, eu estava conversando com uma diretora, ela estava falando para mim que ela discutiu com a professora dela porque a professora falou: "Eu não sei para que essa besteira de a gente ter que planejar tanto. Já vem tudo pronto. É só a gente digitar no sistema. As escolas 3.0. Já está tudo pronto". Quer dizer, ainda tem um equívoco aí do que é planejamento, do que é plano curricular. Então, eu acho que ainda tem algumas questões aí, semânticas e de concepções de trabalho que também ajudam a gente ser atropelados. (Grupo focal, gestores baixo desempenho, Rio de Janeiro)

E, mais à frente, a Entrevistada 15 completa:

Eu conheço pouquíssimos professores que sabem fazer isso: mediar apostila, livro didático, educopédia, entendeu? Mas... 
Eu fiquei doente quando uma diretora falou para mim que a professora dela disse que não sabe o que fazer com tantas horas de centro de estudos. Olha! Olha o impacto que isso pode ter na boca de um político, daqui a pouco. (Grupo focal, gestores baixo desempenho, Rio de Janeiro)

Por outro lado, as "suspeitas" a respeito de uma maior centralização por parte das instâncias superiores de governo institucional, assim como a implementação de projetos elaborados sem a participação dos sujeitos diretamente implicados nas escolas, mas apenas "aplicados" nesses espaços, aparecem confirmadas pela Entrevistada 1:

A relação com a SME mudou um pouco, porque é tudo muito descentralizado para as CREs. Agora é menos [...]. Hoje centralizamos mais. Hoje tentamos fazer o caminho contrário, tentar trabalhar com projetos maiores, sem contar que as CREs continuam fazendo o que acham necessário dentro dos seus espaços, com as suas caraterísticas, muito diferentes, com demandas diferentes. Mas, hoje, a gente acha que mesmo com as demandas, cada uma de um jeito, a gente deve ter um referencial pedagógico forte, mas, hoje, esse trabalho é maior do que era. Tem muita interferência da CRE no desempenho, porque ela gerencia os projetos para as escolas e tal. Mas a CRE tem que ter essa visão. Mas, ao mesmo tempo, lá vem a escola achando que a CRE a está perseguindo. (Grupo focal, gestor SME)

A centralização de um planejamento atrelado à avaliação, mas que dispensa a participação dos sujeitos diretamente envolvidos no cotidiano escolar, no entanto, gera também alguns efeitos que desorientam e, inclusive, anulam a ação pedagógica competente de algumas escolas. Esse é o caso apresentado pelo Entrevistado 14:

No Rio, a gente tem uma realidade num dia, no outro já tem outra... Vem uma coisa em cima de você, é uma resolução, um decreto. É como essa verba do $\mathrm{PDE},{ }^{17}$ a gente previu, ficou um ano e pouco trabalhando, planejando: "Vai ser aplicado aqui, ali", 17 Plano de Desenvolvimento da Escola. aí você vê... Tudo mudou. Já vamos atender de outra forma em outro segmento no ano que vem, então, planejamos uma coisa que visava atender até o segmento que já não estará mais no ano que vem. (Grupo focal, gestores alto desempenho, Rio de Janeiro) 
Paralelamente, outras situações similares, vinculadas à utilização padronizada de critérios da administração central, também surpreendem as gestões escolares.

Entrevistada 4: Não, a CRE fala assim: "você entrou no PDE, tua escola tá mal", porque o PDE é um plus, é um recurso a mais, né, para você dar conta do pedagógico, do que tá acontecendo na escola, eu vi de outra forma, eu falei para os professores: "Graças a Deus, então, que a gente agora vai ter dinheiro para comprar material para desenvolver os projetos, né?"

Entrevistada 5: Às vezes eu queria ser a pior escola para ter dinheiro...

Entrevistada 4: Pois é, não é, professora? Então, a gente recebeu por conta dessa questão da reprovação. Nós fomos "punidos" com PDE, com Mais Educação, é mais verba, é mais... Tá ótimo. A escola agora tá com um recurso. (Grupo focal, gestores alto desempenho, Rio de Janeiro)

A percepção e o conhecimento desses critérios decisionais, em especial em função da captação de recursos para as escolas e/ou seus funcionários, propiciam o desenvolvimento de outro tipo de ação, diferente da inércia passiva, mas, dissimuladamente estratégica, que podemos denominar de estratagema, ou seja, o engano calculado (MATUS, 1987, p. 103). Estratégia que o ator impõe a si mesmo como regra de jogo e que responde a um estilo político que "define as fronteiras do permitido e do proibido, e estrutura suas próprias normas de ética. Define com um perfil muito particular o modo de fazer e aceitar a política” (MATUS, 1996, p. 17). Vejamos:

Entrevistado 11: Porque a nota da [escola] L. era 3.0. Em 2007, foi 4.3 [...]. Aí, agora, a meta era atingir 3.4. Nós atingimos 4.2, 40\%. Aí, os professores disseram: "Nós crescemos demais". Quer dizer, em 2013, de 4.2 vai ter que chegar a 4.6, aí, talvez, não vai conseguir e não vai receber o $14^{\circ}$. (Grupo focal, gestores baixo desempenho, Rio de Janeiro)

E, mais à frente, completa: "Vocês tinham que ter ensinado só um pouquinho para crescer só um pouquinho, para não crescer muito". Esse estratagema de controle do cresci- 
mento do Ideb em função de ter chances de receber o $14^{\circ}$ salário em mais de uma oportunidade, apesar de a escola ter condições de dar esse "salto de qualidade", associa-se a outros, que apresentamos nos parágrafos a seguir. Nesses casos, destinados a elevar os indicadores sem melhorar a eficácia escolar, solicitando, por exemplo, aos estudantes com maiores dificuldades de aprendizagem que não compareçam à escola no dia da prova, como explica o Entrevistado 17:

"Então, você tem histórias escabrosas. Gente que você tinha um conceito... 'Ó, hoje é a avaliação externa, quem tem conceito I fica em casa', aquele 'izinho' que... Então tem isso, então tem várias histórias em cima disso..." (Grupo focal, gestores baixo desempenho, Rio de Janeiro)

Da mesma forma, outras escolas parecem estar escolhendo o "atalho"18 de focalizar um trabalho pedagógico mais eficiente apenas nas turmas que realizarão as provas, como explica a Entrevistada 15:

A gente tem escolas que preparam e que já pensam a sua organização escolar a partir de quem vai pegar as turmas que vão ser avaliadas porque são turmas que vão levar a nota e dizer como é que eu estou. É claro que esta avaliação não diz como é que a gente está. Também não digo que ela não tem que acontecer, não. (Grupo focal, gestores baixo desempenho, Rio de Janeiro)

Por fim, apesar de ilegal, a seleção de alunos para ingresso e permanência na escola parece estar sendo um dos estratagemas das escolas, em especial daquelas com alto desempenho, como denunciam as falas a seguir.

Entrevistada 5: Aí, quando você vai transferir um aluno: "É um bom aluno? É um aluno I? É um aluno B?". Porque tá assim, né, nesse nível. Então é complicado. (Grupo focal, gestores alto desempenho, Rio de Janeiro)

Entrevistada 12: Nós temos bastante escola bem colocada, mas nós temos várias críticas sobre as escolas, são algumas escolas que selecionam alunos e tal. Então, são escolas que nós temos dez olhos para o outro lado. Então, às vezes a gente olha as bem colocadas e a gente sabe que são escolas assim. (Grupo focal, gestores CRE)
18 Não podemos deixar de indicar que as práticas descritas - seleção de alunos, cálculo para controle dos índices, escolha de alunos para realização de provas - que estamos chamando de "atalhos" também são classificáveis como "jeitinhos", no sentido proposto por Roberto Da Matta (1983). 
A diversidade de ações evidenciadas ao longo desses relatos nos mostra, então, os diferentes entendimentos dos sujeitos sobre as finalidades das avaliações externas e a produção de indicadores educacionais. Também evidencia as interpretações sobre sua função como agentes do sistema educacional, ou seja, sobre o desempenho de suas funções tanto como docentes quanto como funcionários públicos, questionando as diversas concepções sobre a profissão docente.

\section{CONSIDERAÇÕES FINAIS}

A análise dos dados descritos neste artigo permite indicar três questões associadas à recepção das avaliações no cotidiano escolar. Inicialmente, é possível apontar desconhecimento por parte de gestores com relação aos aspectos técnicos das avaliações. Encontramos, em todas as instâncias da gestão, falas truncadas sobre as avaliações externas e os índices por elas produzidos.

Outro aspecto é o conjunto de dissonâncias presentes nas falas de gestores. Foi possível perceber que as cobranças relacionadas ao desempenho das escolas seguem o que uma gestora classificou como "efeito dominó": um conjunto de cobranças sucessivas que afetam os agentes de acordo com a posição que ocupam na hierarquia da gestão e/ou das escolas. Conforme indicado, gestores centrais sofrem pressões, pressionam gestores intermediários, que cobram dos gestores de unidades escolares, que, ao final, exigem dos professores.

Finalmente, como resultado dessa conversa desafinada, os mais diversos "jeitinhos" e estratagemas são utilizados como forma de enfrentar os problemas considerados pontuais. Percebemos que os gestores entendem que determinadas ações - como impedir reprovações e/ou que alunos de menor desempenho façam as provas - resultam em aumentos artificiais nos índices. Essas estratégias acabam por criar uma visão equivocada sobre o desempenho das escolas e dos sistemas de ensino. É claro que também mapeamos falas que indicam reconhecimento e valorização dos dados, inclusive dos desafios trazidos por eles. 
Ao final, não é possível afirmar, evidentemente, que a ampliação do conhecimento técnico eliminaria os "jeitinhos" e os estratagemas. Porém, a título de hipótese, podemos indicar que uma maior capacitação para o uso de dados reduziria as sombras e os espaços nebulosos associados aos sistemas nacionais e locais de avaliação externa.

\section{REFERÊNCIAS}

ALVES, Fátima. Qualidade da educação fundamental: integrando desempenho e fluxo escolar. Ensaio: Avaliação e Políticas Públicas em Educação, Rio de Janeiro, v. 15, n. 57, p. 525-542, 2007.

BARBOSA, Lívia. 0 jeitinho brasileiro: a arte de ser mais igual que os outros. Rio de Janeiro: Campus, 1982.

BONAMINO, Alicia. Tempos de avaliação educacional: o Saeb, seus agentes, referências e tendências. Rio de Janeiro: Quartet, 2002.

BONAMINO, Alicia; COSCARELLI, Carla; FRANCO, Creso. Avaliação e letramento: concepções de aluno letrado subjacentes ao Saeb e ao Pisa. Educação \& Sociedade, Campinas, v. 23, n. 81, p. 91-113, 2002.

BONAMINO, Alicia; SOUSA, Sandra Z. Três gerações de avaliação da educação básica no Brasil: interfaces com o currículo da/na escola. Educação e Pesquisa, São Paulo, v. 38, n. 2, p. 373-388, 2012.

BROOKE, Nigel; CUNHA, Maria Amália de A. A avaliação externa como instrumento da gestão educacional nos estados. Estudos e Pesquisas Educacionais, São Paulo, v. 2, p. 17-79, 2011. Disponível em: <http://www. fvc.org.br/estudos-e-pesquisas/avulsas/\%20avaliacao-externa-instrumentogestao-educacional-estados.shtml>. Acesso em: 08 jul. 2014.

CARVALHO, Gisele F. S.; MACEDO, Maria do Socorro A. N. Avaliação oficial: o que dizem os professores sobre o impacto na prática docente. Educação e Pesquisa, São Paulo, v. 37, n. 3, p. 549-564, 2011.

DA MATTA, Roberto. Carnavais, malandros e heróis. Rio de Janeiro: Guanabara, 1983.

FERNANDES, Maria José da S. As recentes reformas educacionais paulistas na visão dos professores. Educação em Revista, Belo Horizonte, v. 26, n. 3 , p. 75-101, dez. 2010.

FONTANIVE, Nilma. O uso pedagógico dos testes. In: SOUZA, Alberto de M. (Org.). Dimensões da avaliação educacional. Petrópolis: Vozes, 2005.

FRANCO, Creso; BONAMINO, Alicia. Iniciativas recentes de avaliação da qualidade da educação no Brasil. In: FRANCO, Creso (Org.). Avaliação, ciclos e promoção na educação. Porto Alegre: Artmed, 2001. p. 15-28. 
FREITAS, Luiz Carlos de. Os reformadores empresariais da educação: da desmoralização do magistério à destruição do sistema público de educação. Educação \& Sociedade, São Paulo, v. 33, n. 119, p. 379-404, 2012. Disponível em: <http://www.scielo.br/pdf/es/v33n119/a04v33n119.pdf>. Acesso em: 21 jul. 2014.

LÉVI-STRAUSS, Claude. Tristes trópicos. Lisboa: Edições 70, 1981.

MANDINACH, Ellen B.; GUMMER, Edith S. A Systemic View of Implementing Data Literacy in Educator Preparation. Educational Researcher, v. 42, p. 30-37, Jan./Feb. 2013.

MANDINACH, Ellen B.; HONEY, Margaret; LIGHT, Daniel. A Theoretical Framework for Data-Driven-Decision Making. Paper presented at American Educational Research Association, San Francisco, California, 2006.

MARSH, Julie; PANE, John F.; HAMILTON, Laura S. Making sense of data-driven decision making in education: evidence from recent RAND research. RAND Occasional Papel (OP-170-EDU). Santa Monica, CA: RAND, 2006.

MARTINS, Angela M.; SOUSA, Sandra Z. A produção científica sobre avaliação educacional e gestão de sistemas e de escolas: o campo da questão entre 2000 e 2008. Ensaio: Avaliação e Políticas Públicas em Educação, Rio de Janeiro, v. 20, n. 74, p. 9-26, 2012.

MATUS, Carlos. Política, planificación y gobierno. Caracas: Fundación Altadir, 1987.

. Estratégias políticas: Chimpanzé, Machiavello e Gandhi. São Paulo: Fundap, 1996.

MESQUITA, Silvana. Os resultados do Ideb no cotidiano escolar. Ensaio: Avaliação e Políticas Públicas em Educação, Rio de Janeiro, v. 20, n. 76, p. 587-606, set. 2012.

PIMENTA, Cláudia O. Bons resultados no Ideb: fatores explicativos do município de Indaiatuba. In: SIMPÓSIO BRASILEIRO, 25.; CONGRESSO IBERO-AMERICANO DE POLÍTICA E ADMINISTRAÇÃO DA EDUCAÇÃO, 2., 2011. São Paulo. Cadernos Anpae. São Paulo: Anpae, 2011. v. 1. p. 1-13.

ROSISTOLATO, Rodrigo P. R.; PRADO, Ana P. do. Os profissionais da educação e as avaliações externas de aprendizagem: uma comparação entre Rio de Janeiro e Duque de Caxias. Roteiro, Rio de Janeiro, v. 39, p. 311-329, 2014.

SILVA, Vandré G. et al. Uso da avaliação externa por equipes gestoras e profissionais docentes: um estudo em quatro redes de ensino público. São Paulo: FCC/SEP, 2013. (Textos FCC, v. 38).

SOARES, José Francisco. O índice de desenvolvimento da educação de São Paulo - Idesp: bases metodológicas. São Paulo em Perspectiva, São Paulo, v. 23, n. 1, p. 29-41, 2009.

SOUSA, Sandra Z. Possíveis impactos das políticas de avaliação no currículo escolar. Cadernos de Pesquisa, São Paulo, n. 119, p. 175-190, 2003. 
RODRIGO ROSISTOLATO

Professor do Programa de Pós-Graduação em Educação da

Universidade Federal do Rio de Janeiro (PPGE/UFRJ),

Rio de Janeiro, Rio de Janeiro, Brasil

rosistolato@hotmail.com

ANA PIRES DO PRADO

Professora da Faculdade de Educação da

Universidade Federal do Rio de Janeiro (FE/UFRJ),

Rio de Janeiro, Rio de Janeiro, Brasil

anapprado@yahoo.com

\section{SILVINA JULIA FERNÁNDEZ}

Professora da Faculdade de Educação da

Universidade Federal do Rio de Janeiro (FE/UFRJ),

Rio de Janeiro, Rio de Janeiro, Brasil

silvinajf@gmail.com 